\title{
Stabilization of Empty Fruit Bunch derived Bio-oil using Solvents
}

\author{
Chung Loong Yiin ${ }^{1}$, Suzana Yusup ${ }^{* 2}$, Mustakimah Mohamed ${ }^{3}$, Parncheewa \\ Udomsap $^{4}$, Boonyawan Yoosuk ${ }^{5}$, Sittha Sukkasi ${ }^{6}$ \\ ${ }^{1}$ Biomass Processing Technology Cluster, Center for Biofuel and Biochemical Research, Chemical \\ Engineering Department, Universiti Teknologi PETRONAS, 31750 Tronoh, Perak, Malaysia \\ e-mail: ychungloong2009@gmail.com \\ ${ }^{2}$ Biomass Processing Technology Cluster, Center for Biofuel and Biochemical Research, Chemical \\ Engineering Department, Universiti Teknologi PETRONAS, 31750 Tronoh, Perak, Malaysia \\ e-mail: drsuzana_yusuf@petronas.com.my \\ ${ }^{3}$ Biomass Processing Technology Cluster, Center for Biofuel and Biochemical Research, Chemical \\ Engineering Department, Universiti Teknologi PETRONAS, 31750 Tronoh, Perak, Malaysia \\ e-mail: mustakimahmohamed@gmail.com \\ ${ }^{4}$ National Metal and Materials Technology Center, 114 Thailand Science Park (TSP), Phahonyothin Road, \\ Khlong Nueng, Khlong Luang, Pathum Thani 12120, Thailand \\ e-mail: parncheu@mtec.or.th \\ ${ }^{5}$ National Metal and Materials Technology Center, 114 Thailand Science Park (TSP), Phahonyothin Road, \\ Khlong Nueng, Khlong Luang, Pathum Thani 12120, Thailand \\ e-mail: yoosuk.b@gmail.com \\ ${ }^{6}$ National Metal and Materials Technology Center, 114 Thailand Science Park (TSP), Phahonyothin Road, \\ Khlong Nueng, Khlong Luang, Pathum Thani 12120, Thailand \\ e-mail: sittha@gmail.com
}

Cite as: Yiin, C. L., Yusup, S., Mohamed, M., Udomsap, P., Yoosuk, B., Sukkasi, S., Stabilization of Empty Fruit

Bunch derived Bio-oil using Solvents, J. sustain. dev. energy water environ. syst., 4(1), pp 38-47, 2016, DOI: http://dx.doi.org/10.13044/j.sdewes.2016.04.0004

\begin{abstract}
The intention of this research was to select the ideal condition for accelerated aging of bio-oil and the consequences of additive in stabilizing the bio-oil. The bio-oil was produced from the catalytic pyrolysis of empty fruit bunch. The optimum reaction conditions applied to obtain the utmost bio-oil yield were $5 \mathrm{wt} \%$ of $\mathrm{H}-\mathrm{Y}$ catalyst at reaction temperature of $500{ }^{\circ} \mathrm{C}$ and nitrogen flow rate of $100 \mathrm{ml} / \mathrm{min}$. A $10 \mathrm{wt} \%$ of solvents including acetone, ethanol, and ethyl acetate were used to study the bio-oil's stability. All the test samples were subjected to accelerated aging at temperature of $80{ }^{\circ} \mathrm{C}$ for 7 days. The properties of samples used as the indicator of aging were viscosity and water content. The effectiveness of solvents increased in the following order: acetone, ethyl acetate, and 95 vol\% ethanol. Based on the result of Gas Chromatography-Mass Spectrometry (GC-MS), it could impede the chain of polymerization by converting the active units in the oligomer chain to inactive units. The solvent reacted to form low molecular weight products which resulted in lower viscosity and lessen the water content in bio-oil. Addition of $95 \mathrm{vol} \%$ ethanol also inhibited phase separation.
\end{abstract}

\section{KEYWORDS}

Stabilization, Empty fruit bunch, Catalytic pyrolysis, Accelerated aging, Solvents, Gas Chromatography-Mass Spectrometry (GC-MS).

\section{INTRODUCTION}

Lignocellulosic biomass has been used for the production of renewable fuels and chemicals. This has caused increasing attention due to shortage of oil reserves, enhanced fuel demand worldwide, increased climate concerns, and the inherent conflict between

* Corresponding author 
food prices and converting edible carbohydrates to ethanol or plant oils to bio-diesel [1]. Biomass is the most common form of renewable energy and generates very low net greenhouse emissions. The energy from biomass can be obtained by various techniques, such as combustion or by upgrading it into a more valuable fuel, gas or oil. Biomass can also be transformed into a source of value-added products for the chemical industry by using a thermochemical method such as pyrolysis of bio-oil. Nonetheless, several drawbacks of bio-oil severely limit its potential to replace or supplement high-grade transportation fuels. These include low heating values, high corrosiveness, high water content, thermal instability and immiscibility with hydrocarbon fuels, etc. [2]. Thus, bio-oil has to be upgraded before using it as a fuel. Moens et al. [3] pointed out that lignin compound will be formed in bio-oil after it is left for a few weeks or months. During storage the reactive components can interact to form larger molecules and altered its properties due to oxidation and thermal degradation.

Oxidation leads to polymerization resulting in an increase of viscosity. On the other hand, thermal degradation leads to partial decomposition of components and can result in loss of volatiles which further caused the bio-oil's viscosity to increase. The High-Molecular-Mass (HMM) fraction of water-insolubles which are lignin-derived material will be increased due to polymerization and condensation reactions of carbohydrate constituents, aldehydes and ketones. Increment of HMM lignin fraction will increase the density of bio-oil as well. This phenomenon is due to the reason that of molecular weight increases during storage results from etherification and esterification occurring between hydroxyl, carbonyl and carboxyl group components. Condensation reactions in bio-oil will result in the formation of water as byproduct and further reduces its heating value [3].

Palm oil production is vital for the economy of Malaysia, which is the world's second largest producer of the commodity. It covers about $59 \%$ of the world's needs and $23 \%$ of Empty Fruit Bunch (EFB) can be obtained from the substantial fresh fruit bunch produced. Malaysia has generated a lot of oil palm biomass residues in the form of empty fruit bunch, mesocarp fibre, palm kernel shell and palm oil mill effluent [4]. Empty fruit bunch can be utilized as the feedstock for biomass pyrolysis. The reaction condition for the bio-oil used are 5 weight percent of $\mathrm{H}-\mathrm{Y}$ zeolite catalyst at temperature of $500{ }^{\circ} \mathrm{C}$ and nitrogen flow rate of $100 \mathrm{ml} / \mathrm{min}[5,6]$. Catalytic pyrolysis offers some advantages over slow pyrolysis. The reaction can be improved and enhanced by the introduction of catalyst. Since pyrolysis requires the breaking of carbon-carbon bonds, the introduction of catalyst is able to catalyze the reaction and to facilitate the cracking reactions and de-oxygenation reaction, improve the quality of bio-oil produced compared to that of slow pyrolysis and thus the downstream upgrading processes is less expensive [7]. This process is able to remove oxygenated groups in bio-oil and improves the stability of bio-oil.

Introduction of catalyst in catalytic pyrolysis decreased the amount of organic yield (bio-oil) and increased the amount of gas yield, water content and Polyaromatic Hydrocarbons (PAHs) [8]. The oxygenated compounds in the bio-oil undergo dehydration, decarboxylation, cracking, aromatization, alkylation, condensation and polymerization with deoxygenation simultaneously [9]. Higher water content reduced the heating value of the bio-oil [10]. Besides, the most important factor driving the aging rate is temperature. Heating bio-oil to $60{ }^{\circ} \mathrm{C}$ or higher will promote internal reactions and polymerization that can be significant over a prolonged period [11]. Elevated temperatures increase the rate of the aging reactions, forming higher molecular weight compounds [12]. Solvents play an important role in maintaining the bio-oil's stability. Organic solvents can also inhibit the chain of polymerization by converting the active 
units in the oligomer chain to inactive units which are acetone, biodiesel, ethanol, ethyl acetate and methanol [13].

Table 1 shows that the bio-oils have the following undesired properties for fuel applications when compared to petroleum fuel oil which has high water content, high viscosity and high oxygen content which leads to low heating value. These undesired properties have limited range of bio-oil application. The differences in processing conditions and feedstock result in significant differences in the product yield and product composition of bio-oils. Bio-oil is highly oxygenated, acidic and corrosive to common materials, thermally and chemically instable, as well as non-miscible with petroleum fuels due to its unique composition [14]. These fuel properties limited the bio-oil to be used directly only in boilers and furnaces. Bio-oil is hard to be directly used in diesel engines and gas turbines [15]. Various physical or chemical methods have been proposed to upgrade bio-oil.

Table 1. Physical properties of bio-oil and petroleum fuel [16]

\begin{tabular}{cccc}
\hline \multirow{2}{*}{ Physical properties } & \multicolumn{3}{c}{ Value } \\
\cline { 2 - 4 } & $\begin{array}{c}\text { Bio-oil } \\
\text { (Jatropha) }\end{array}$ & $\begin{array}{c}\text { Bio-oil } \\
(\mathrm{EFB})\end{array}$ & $\begin{array}{c}\text { Petroleum } \\
\text { fuel }\end{array}$ \\
\hline Moisture content $[\mathrm{wt} \%]$ & $15.0-30.0$ & 50.0 & 0.1 \\
Heating value $[\mathrm{MJ} / \mathrm{kg}]$ & $16.0-19.0$ & 10.4 & 40.0 \\
Viscosity at $40^{\circ} \mathrm{C}[\mathrm{cP}]$ & $40.0-100.0$ & 45.5 & 18.0 \\
Elemental composition [wt\%] & & & \\
\hline Carbon & $54.0-58.0$ & 25.3 & 85.0 \\
Hydrogen & $5.5-7.0$ & 9.3 & 11.0 \\
Oxygen & $35.0-40.0$ & 64.6 & 10.0 \\
Nitrogen & $0-0.2$ & 0.3 & 0.3 \\
\hline
\end{tabular}

Hence this research was aimed to stabilize the empty fruit bunch derived bio-oil by enhancing the properties of bio-oil such as water content and viscosity using solvents. The solvents used were ethyl acetate, acetone and ethanol of 95 vol\% [13]. The chosen optimum conditions for aging of bio-oil were temperature of $80^{\circ} \mathrm{C}$ and duration of 7 days $[2,13,17-20]$. The viscosity, water content and chemical compositions of the stabilized bio-oil were analyzed.

\section{METHODOLOGY AND MATERIALS}

\section{Materials and sample preparation}

The source of empty fruit bunches was obtained from palm tree plantation area "Kilang Sawit FELCRA Berhad Nasaruddin, KM 37, Jalan Tronoh, 32600 Bota, Perak, Malaysia". These empty fruit bunches were washed and dried in an oven at $100{ }^{\circ} \mathrm{C}$ for 3 days. The dried EFB was chopped and cut into smaller pieces. The sand and dust particles were cleaned by using water and then dried in the oven at $100{ }^{\circ} \mathrm{C}$ for $24 \mathrm{~h}$. The dried EFB was then grinded with FRITSCH Cutting Mill to particle size below $500 \mu \mathrm{m}$. The grinded EFB was sieved to get the desired particle size of $<500 \mu \mathrm{m}$. Table 2 shows the measured properties of EFB.

Ultimate analysis of the EFB was carried out using LECO 932 CHNS Analyzer and the Higher Heating Value (HHV) was measured using IKA C5000 Bomb Calorimeter. The zeolite catalyst used in the catalytic pyrolysis was purchased from Sigma-Aldrich with surface area of $780 \mathrm{~m}^{2} / \mathrm{g}, 30 \mathrm{wt} \%$ of $\mathrm{SiO}_{2} / \mathrm{Al}_{2} \mathrm{O}_{3}$ and pore size of $7.4 \times 7.4 \AA$ [21]. 
The solvents (EMSURE ${ }^{\circledR}$ ACS) acetone and ethyl acetate were obtained from Merck KgaA whereas ethanol of $95 \mathrm{vol} \%$ was purchased from $\mathrm{HmbG}$ chemicals.

Table 2. Properties of EFB ( $\mathrm{mf} w \mathrm{t} \%)$

\begin{tabular}{cc}
\hline Properties & Measured value \\
\hline Ultimate analysis & \\
\hline Carbon & 46.830 \\
Hydrogen & 6.277 \\
Nitrogen & 0.664 \\
Sulfur & 0.237 \\
Oxygen (by difference) & 45.992 \\
HHV [MJ/kg] & 19.643 \\
\hline
\end{tabular}

\section{Procedure}

Catalytic pyrolysis of Empty Fruit Bunch (EFB). In each run, about 15 gram of dried EFB was mixed with zeolite catalyst and loaded into the borosilicate glass tube. The glass tube was inserted inside the furnace. A glass wool was used to prevent the elutriation of reactant particles and blocked the gas inlet to the condenser. Nitrogen gas was allowed to flow through the tube for a few minutes to remove any oxygen presents before the reaction. The desired temperature of the reaction of $500{ }^{\circ} \mathrm{C}$, the furnace heating rate of 20 ${ }^{\circ} \mathrm{C} / \mathrm{min}$ and the nitrogen gas flow rate of $100 \mathrm{ml} / \mathrm{min}$ were set. During the pyrolysis, the pyrolysis vapor produced was carried out by the nitrogen gas and passed through an ice bath condenser, where the condensable vapor was condensed to form bio-oil as shown in Figure 1.

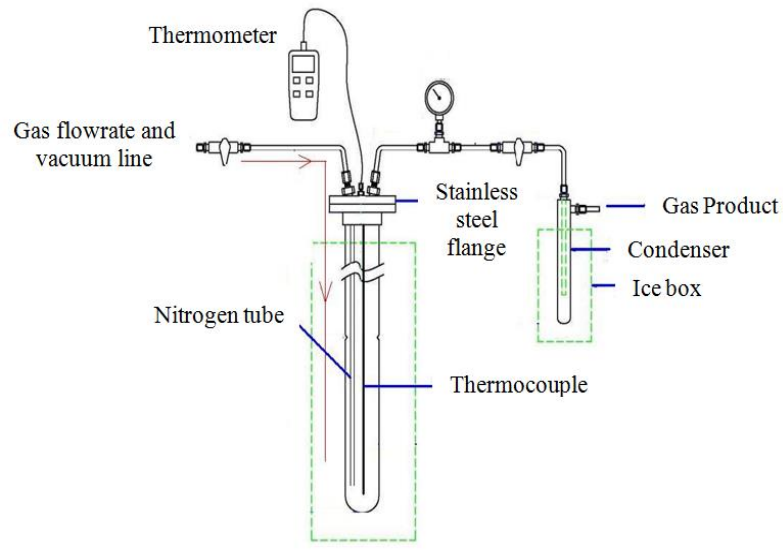

Figure 1. Semi-batch reactor

The reaction required about $35 \mathrm{~min}$. The weight of the bio-oil produced was determined by measuring the difference between the weight of the condenser before and after the experiment. The liquid yield was calculated using eq. (1) below [22]:

$$
\text { Liquid yield }(\text { wt } \%)=\frac{\text { weight of bio }- \text { oil produced }}{\text { weight of biomass }} \times 100
$$

The bio-oil obtained from all the experimental runs was stored in a container and placed in a refrigerator in order to slow down the rate of aging. 
Stabilization of EFB derived bio-oil. The aging of EFB derived bio-oil was studied at $80{ }^{\circ} \mathrm{C}$ for 7 days. $10 \mathrm{wt} \%$ of ethyl acetate, acetone and ethanol of $95 \mathrm{vol} \%$ were added to the EFB derived bio-oil in separate samples. The percentage change in viscosity and water content of the bio-oil with the selected solvents were calculated based on eq. (2) and eq. (3) respectively:

$$
\% \text { change in viscosity }=\frac{\Delta \text { viscosityof original and stabilized bio }- \text { oil }}{\text { viscosity of original bio }- \text { oil }} \times 100
$$

$$
\% \text { change in water content }=\frac{\Delta \text { water content of original and stabilized bio }- \text { oil }}{\text { water content of original bio }- \text { oil }} \times 100
$$

Characterization of EFB derived bio-oil. Metrohm 870 Karl Fischer Titrino Plus was used to determine the water content of bio-oil samples. It took into account of two dosinos with their dosing units mounted directly onto reagent bottles that are located on the instrument. On the other hand, the viscosity of the bio-oil in this study was measured with Brookfield CAP 2000+ Viscometer. The Gas Chromatography-Mass Spectrometry (GC-MS) analyses were conducted on samples diluted in acetone using GCMS-QP2010 Plus.

\section{RESULTS AND DISCUSSION}

\section{Effects of solvents on bio-oil's stability}

The chosen chemical solvents, ethanol of $95 \mathrm{vol} \%$, acetone and ethyl acetate were mixed homogeneously with the bio-oil. The percentage changed in viscosity and water content of bio-oil, with and without solvents, after subjected to accelerate aging are presented in Figure 2 and Figure 3 respectively. Figure 2 shows that after the accelerated aging at $80{ }^{\circ} \mathrm{C}$ for 7 days, the percentage change in viscosity of bio-oil with solvents decreased compared to pure bio-oil. This indicated that the solvents were able to increase the stability of bio-oil. The percentages change of viscosity of bio-oil with ethyl acetate, acetone and ethanol were $64.60 \%, 79.09 \%$ and $38.31 \%$ respectively.

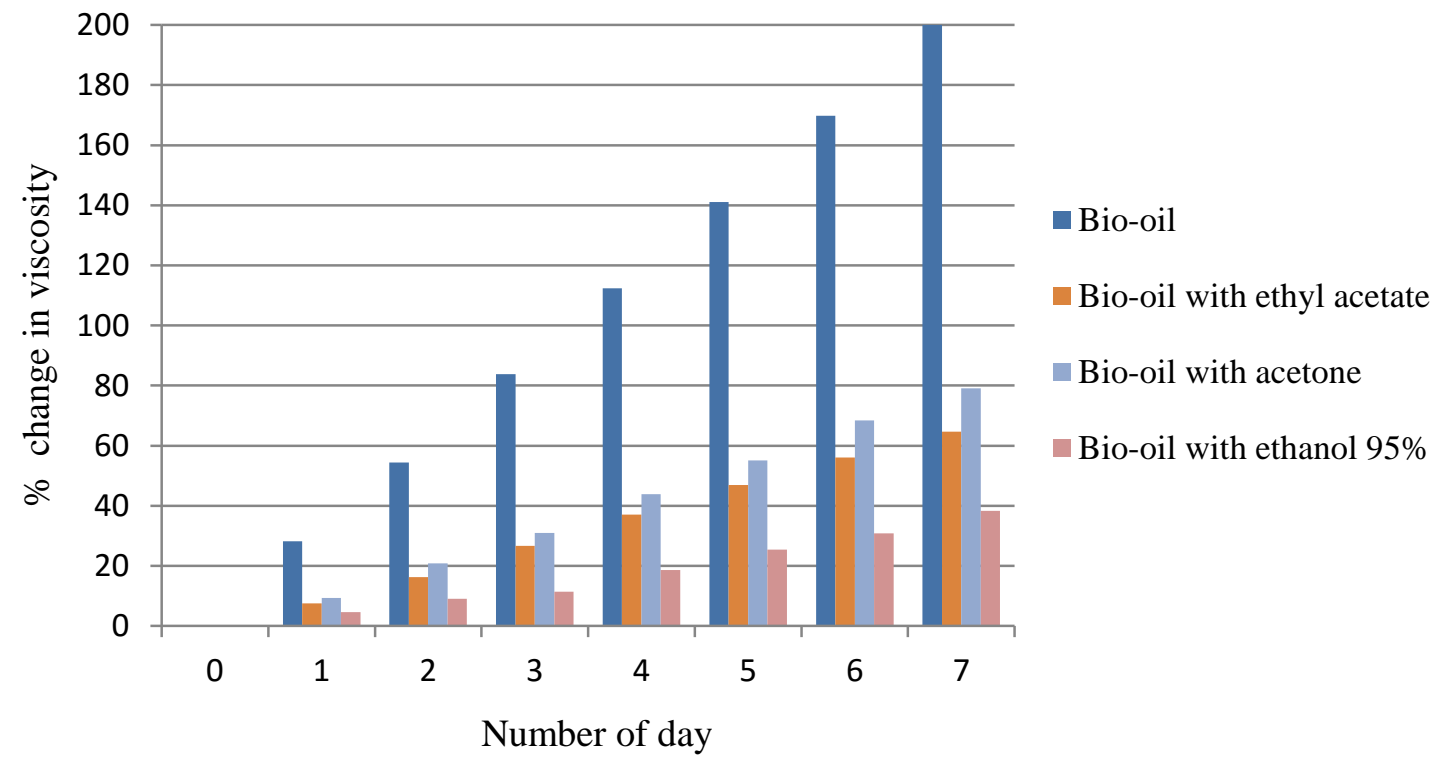

Figure 2. Percentage change in viscosity of bio-oil with and without solvents 
Based on Figure 3, the water content of bio-oil was reduced with the addition of solvents where the percentage changed of water content of bio-oil with ethyl acetate, acetone and ethanol of 95 vol\% were $4.10 \%, 6.63 \%$ and $0.75 \%$ respectively. The results were comparable to the work of Osama et al. [23] as he investigated that by adding 2 $\mathrm{wt} \%, 5 \%, 10 \%$, and $20 \%$ of ethanol to a hardwood bio-oil and observed that the initial viscosity of the bio-oil at $50{ }^{\circ} \mathrm{C}$ decreased from 50 cost with absence of ethanol to 10 cost with presence of $20 \%$ ethanol. After aging at $50{ }^{\circ} \mathrm{C}$ for 7 days, the increased in viscosity of the neat bio-oil was 3.5 cost/day compared to $0.4 \mathrm{cost} /$ day for a mixture of $5 \mathrm{wt} \%$ ethanol in bio-oil.

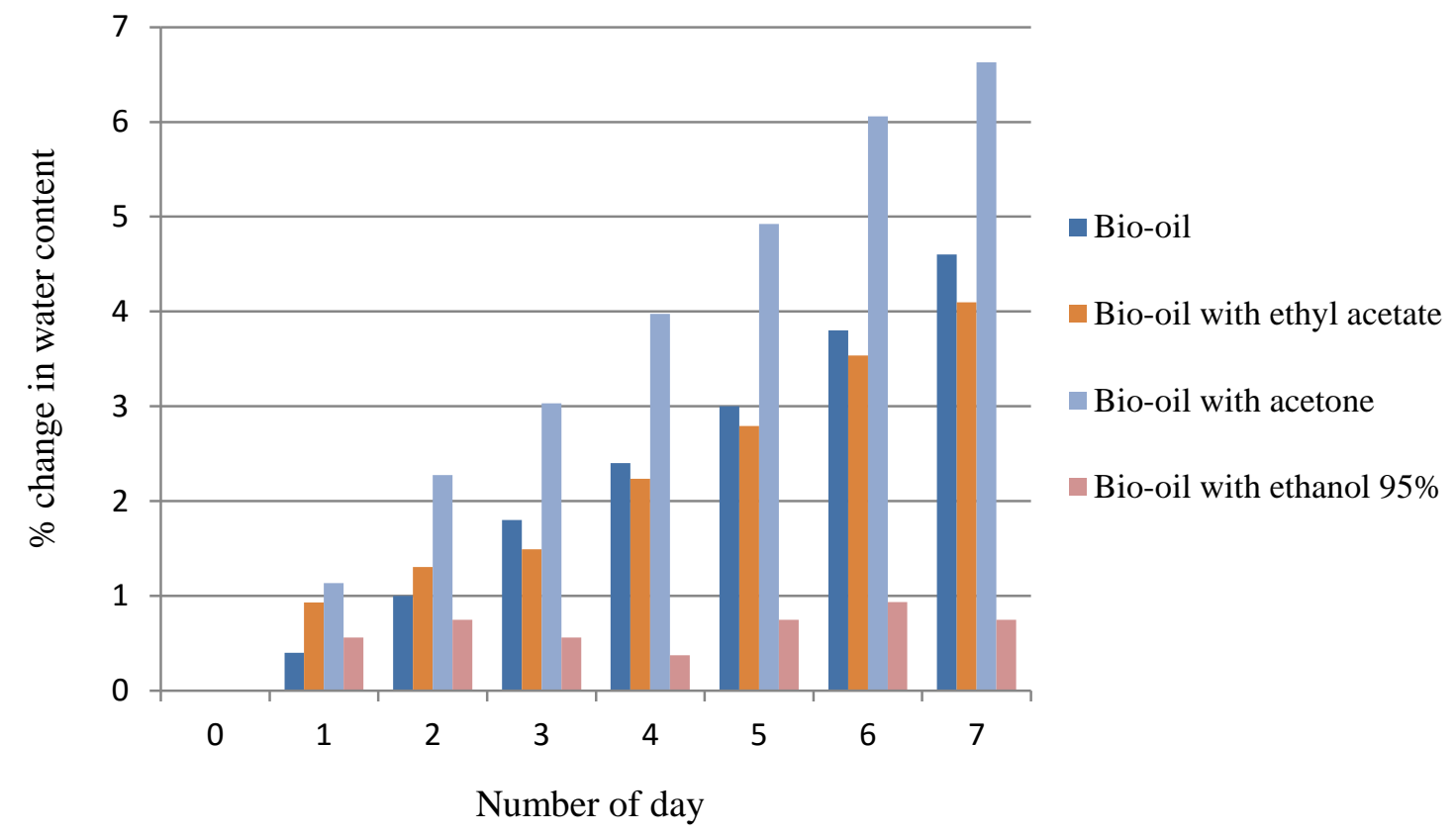

Figure 3. Percentage change in water content of bio-oil with and without solvents

The effectiveness of solvent increased in the following order: acetone, ethyl acetate, and ethanol of 95 vol\%. For bio-oil blended with solvents, no phase separation was observed after 7 days of accelerated aging. It showed that addition of ethanol to pure bio-oil inhibited phase separation. This was particularly important for bio-oil storage at high temperatures. Gas Chromatography-Mass Spectrometry (GC-MS) analysis was conducted on bio-oil with ethanol to identify the compounds that presence in the bio-oil.

\section{Gas Chromatography-Mass Spectrometry (GC-MS)}

Diebold [2] investigated that bio-oil with high molecular weight of hemiacetals, acetals, and esters would shift the equilibrium composition to a mixture with a lower molecular weight and viscosity by adding a low molecular weight alcohol. This could be important in stabilizing the bio-oil by four mechanisms which are reducing the concentration of reactive aldehydes, by converting more of them to less reactive, relatively low to moderate molecular-weight hemiacetals and acetals, transacetalizing large hemiacetals and acetals to form lower molecular weight hemiacetals and acetals, converting organic acids to low molecular weight esters and transesterifying large esters to form lower molecular weight esters. The second and fourth mechanisms could be considered to depolymerize the original high molecular weight hemiacetals, acetals, and esters. The chemical compositions of pure bio-oil and bio-oil with ethanol of 95 vol\% were plotted in pie charts as shown in Figure 4 below. 


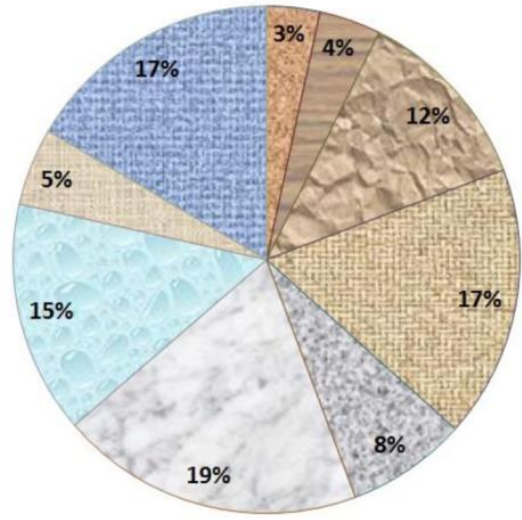

(a) Pure bio-oil

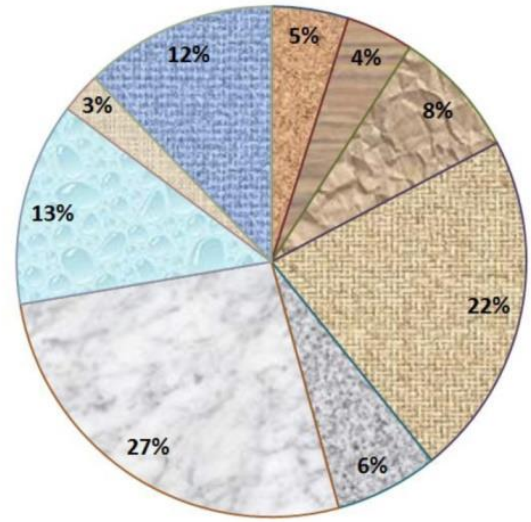

回Alcohol

$\square$ Aromatic Hydrocarbon

$\square$ Ester

回Phenol

$\square$ Furan

$\square$ Carboxylic acid

$\square$ Ketone

Aldehydes

푸 Others (e.g.: Sugars, acetals, furfural, aromatics)

(b) Bio-oil with ethanol of 95 vol \%

Figure 4. Chemical composition of pure bio-oil (a); and bio-oil with ethanol of 95 vol\% (b)

Figure 4 shows that adding ethanol of 95 vol\% to bio-oil shifts the equilibrium composition of bio-oil towards more esters, acetals and water. The formation of esters and water from the reactions between carboxylic acids and ethanol was shown in the eq. (4) as follows:

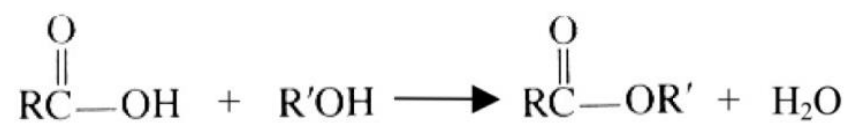

Water was the most abundant compound present in pure bio-oil. Water was miscible with many of the oligomeric lignin derived components due to the solubilising effect of hydrophilic compounds. In addition, the water could not be removed by distillation as there was an azeotrope system formed between the carboxylic acid and water. Thus, conversion of low molecular weight acids into their corresponding esters allowed a large quantity of the water to be removed by distillation.

On the other hand, increased water content encouraged the hydrolysis of ester linked polymers to form lower-molecular-weight products such as furfural and furan. It also converted the reactants to inactive forms. The ethanol could react with the reactive sites in the oligomers that terminated polymerization. Likewise, polymeric esters were transesterified with alcohol to form a lower-molecular-weight methyl ester. The increased in molecular weights of these methyl esters and acetals were relatively low compared to the possible molecular weights that occurs in a real bio-oil with oligomeric hydroxy compounds reacting with oligomeric acids and aldehydes. This proved that addition of low molecular weight reactants reacts with oligomeric bio-oil components to form medium low molecular weight oligomers instead of high molecular weight polymers. Besides, aldehyde groups could also be converted to acetals which reduce the availability for polymerization. The results were analogous with the work of Etzkorn et al. [24]. He explored that unsaturated aldehydes such as acrolein could react with alcohol to form the alkoxy aldehyde, unsaturated acetal or alkoxy acetal according to the reaction shown in eq. (5) as follows:<smiles>[R]OCCO[R2]</smiles>

where $\mathrm{R}$ is an alkyl group. 
Addition of ethanol to bio-oil also inhibited phase separation as there was an absence of low-viscosity water-rich component on the top and a high-viscosity tar-rich layer at the bottom of the bio-oil which confirmed similar findings with the work of Oasmaa et al. [23]. He stated that the stability of bio-oil during storage increased by adding proper solvents.

\section{Catalytic pyrolysis of Empty Fruit Bunch (EFB)}

The estimated bio-oil required for the study of stabilization was produced in 29 runs of experiment. The weight percentage of liquid yield for each run was calculated and tabulated in Table 3. The average liquid yield for catalytic pyrolysis of EFB in this research was $25.73 \mathrm{wt} \%$.

Table 3. Liquid yield (wt\%) for catalytic pyrolysis of EFB

\begin{tabular}{cccc}
\hline No. of run & $\begin{array}{c}\text { Weight of } \\
\text { biomass [g] }\end{array}$ & $\begin{array}{c}\text { Weight of bio-oil } \\
\text { produced [g] }\end{array}$ & Liquid yield [wt\%] \\
\hline 1 & 15.01 & 3.86 & 25.72 \\
2 & 15.00 & 3.91 & 26.07 \\
3 & 15.02 & 3.87 & 25.77 \\
4 & 15.02 & 3.88 & 25.83 \\
5 & 15.03 & 3.88 & 25.82 \\
6 & 15.04 & 3.86 & 25.66 \\
7 & 15.03 & 3.85 & 25.61 \\
8 & 15.01 & 3.82 & 25.44 \\
9 & 15.01 & 3.84 & 25.58 \\
10 & 15.00 & 3.85 & 25.67 \\
11 & 15.03 & 3.86 & 25.68 \\
12 & 15.04 & 3.81 & 25.33 \\
13 & 15.01 & 3.88 & 25.84 \\
14 & 15.02 & 3.90 & 25.97 \\
15 & 15.02 & 3.91 & 26.03 \\
16 & 15.04 & 3.87 & 25.73 \\
17 & 15.03 & 3.85 & 25.62 \\
18 & 15.03 & 3.82 & 25.42 \\
19 & 15.03 & 3.81 & 25.36 \\
20 & 15.05 & 3.80 & 25.25 \\
21 & 15.02 & 3.91 & 26.03 \\
22 & 15.01 & 3.92 & 26.12 \\
23 & 15.01 & 3.86 & 25.71 \\
24 & 15.00 & 3.87 & 25.80 \\
25 & 15.00 & 3.87 & 25.80 \\
26 & 15.00 & 3.85 & 25.67 \\
27 & 15.00 & 3.84 & 25.60 \\
28 & 15.02 & 3.89 & 25.90 \\
29 & 15.00 & 3.90 & 26.00 \\
\hline & Average liquid yield [wt\%] & 25.73 \\
\hline
\end{tabular}

\section{CONCLUSIONS}

In conclusion, the optimum condition for accelerated aging of bio-oil at $80{ }^{\circ} \mathrm{C}$ for 7 days had been applied. At this condition, solvents had been used to stabilize the bio-oil. The solvents used were able to improve the stability of bio-oil in terms of viscosity and water content during aging. The effectiveness of solvents increased in the following 
order: acetone, ethyl acetate and ethanol of 95 vol\%. Organic solvent had great effect on both viscosity and water content of bio-oil. It could inhibit the chain of polymerization by converting the active units in the oligomer chain to inactive units. The solvent reacted to form higher low molecular weight products such as furfural and furan which resulted in lower viscosity and reduced the water content. Besides, addition of ethanol of $95 \mathrm{vol} \%$ also inhibited phase separation.

\section{ACKNOWLEDGEMENTS}

The authors would like to acknowledge Universiti Teknologi PETRONAS for the support given to undertake the research work and Ministry of Education (MOE) for the Long Term Research Grant Scheme (LRGS).

\section{REFERENCES}

1. Amidon, T. E., Wood, C. D., Shupe, A. M., Wang, Y., Graves, M. and Liu, S. J., Biorefinery: Conversion of Woody Biomass to Chemicals, Energy and Materials, $J$. Biobased Mater. Bioenergy, Vol. 2, pp 100-120, 2008, http://dx.doi.org/10.1166/jbmb.2008.302

2. Diebold, J. P., A Review of the Chemical and Physical Mechanisms of the Storage Stability of Fast Pyrolysis Bio-oils, http://home.rmi.net/diebolic, [Accessed: 26-February-2013]

3. Moens, L., Black, S. K., Myers, M. D. and Czernik, S., Study of the Neutralization and Stabilization of a Mixed Hardwood Bio-oil, Energy and Fuels, Vol. 23, pp 2695-2699, 2009, http://dx.doi.org/10.1021/ef8009266

4. Ng, W. P. Q., Hon, L. L., Foo, Y. N., Kamal, M. and Heng, J. E. L., Waste-to-wealth: Green Potential from Palm Biomass in Malaysia, Journal of Cleaner Production, Vol. 34, pp 57-65, 2012, http://dx.doi.org/10.1016/j.jclepro.2012.04.004

5. Sukiran, M. A., Chin, C. M., and Bakar, N. K. A., Bio-oils from Pyrolysis of Oil Palm Empty Fruit Bunches, Am. J. Applied Sci., Vol. 6, pp 869-875, 2009, http://dx.doi.org/10.3844/ajassp.2009.869.875

6. Chan, Y. H., Dang, K. V., Yusup, S., Lim, M. T., Zain, A. M. and Uemura, Y., Studies on Catalytic Pyrolysis of Empty Fruit Bunch (EFB) using Taguchi's L9 Orthogonal Array, Journal of the Energy Institute, Vol. 87, pp 227-234, 2014, http://dx.doi.org/10.1016/j.joei.2014.03.008

7. Gopakumar, S. T., Adhikari, S., Gupta, R. B., Tu, M. and Taylor, S., Production of Hydrocarbon Fuels from Biomass using Catalytic Pyrolysis under Helium and Hydrogen Environments, Bioresource Technology, Vol. 102, pp 6742-6749, 2010, http://dx.doi.org/10.1016/j.biortech.2011.03.104

8. Denghui, W., Rui, X., Huiyan, Z. and Guangying, He., Comparison of Catalytic Pyrolysis of Biomass with MCM-41 and $\mathrm{CaO}$ Catalysts by using TGA-FTIR Analysis, Journal of Analytical and Applied Pyrolysis, Vol. 89, pp 171-177, 2010, http://dx.doi.org/10.1016/j.jaap.2010.07.008

9. French, R. and Czernik, S., Catalytic Pyrolysis of Biomass for Biofuels Production, Fuel Processing Technology, Vol. 91, pp 25-32, 2010, http://dx.doi.org/10.1016/j.fuproc.2009.08.011

10. Crocker, M. E., Thermochemical Conversion of Biomass to Liquid Fuels and Chemicals, United Kingdom: The Royal Society of Chemistry, 2010, http://dx.doi.org/10.1039/9781849732260

11. Corporation D. E. S., Dynamotive; the Bio-oil Information Book, www.wikinvest.com/stock/Dynamotive_Energy_Systems_(DYMTF)/Biooil_Produc tion_Facilities_Markets, 2006. 
12. Eid, A. and Bob, H., Accelerated Aging of Bio-oil from Fast Pyrolysis of Hardwood, Energy Fuels, Vol. 28, pp 3224-3235, 2014, http://dx.doi.org/10.1021/ef500399n

13. Udomsap, P., Yapp, H. Y., Tiong, H. H., Yoosuk, B., Yusup, S., and Sukkasi, S., Towards Stabilization of Bio-oil by Addition of Antioxidants and Solvents, and Emulsification with Conventional Hydrocarbon Fuels, The International Conference \& Utility Exhibition, Thailand, 2011, http://dx.doi.org/10.1109/icuepes.2011.6497720

14. Lu, Q., Li, W. Z. and Zhu, X. F., Overview of Fuel Properties of Biomass Fast Pyrolysis Oils, Energy Convers. Manag., Vol. 50, pp 1376-1383, 2009, http://dx.doi.org/10.1016/j.enconman.2009.01.001

15. Chiaramonti, D., Oasmaa, A. and Solantausta, Y., Power Generation using Fast Pyrolysis Liquids from Biomass, Renew. Sustain. Energy Rev., Vol. 11, pp 1056-1086, 2007, http://dx.doi.org/10.1016/j.rser.2005.07.008

16. Pattiya, A., Bio-oil Production via Fast Pyrolysis of Biomass Residues from Cassava Plants in a Fluidized-bed Reactor, Bioresource Technology, Vol. 102, pp. 1959-1967, 2010, http://dx.doi.org/10.1016/j.biortech.2010.08.117

17. Chaithongdee, D., Chutmanop, J., and Srinophakun, P., Effect of Antioxidants and Additives on the Oxidation Stability of Jatropha Biodiesel, Kasetsart Journal (Natural Science), Vol. 44, pp 243-250, 2010.

18. Karavalakis, G., Hilari, D., Givalou, L., Karonis, D. and Stournas, S., Storage Stability and Ageing Effect of Biodiesel Blends Treated with Different Antioxidants, Energy, Vol. 36, pp 369-374, 2011, http://dx.doi.org/10.1016/j.energy.2010.10.029

19. Boucher, M. E., Chaala, A. and Roy, C., Bio-oils Obtained by Vacuum Pyrolysis of Softwood Bark as a Liquid Fuel for Gas Turbine, Part I: Properties of Bio-oil and its blends with Methanol and a Pyrolytic Aqueous Phase, Biomass and Bioenergy, Vol. 19, pp. 337-350, 2000, http://dx.doi.org/10.1016/S0961-9534(00)00043-X

20. Araujo, S. V., Luna, F. M. T., Rola, Estelio M., Azevedo, Diana C. S., Cavalcante, J. R. and Celio, L., A Rapid Method for Evaluation of the Oxidation Stability of Castor Oil FAME: Influence of Antioxidant Type and Concentration, Fuel Processing $\begin{array}{llllll}\text { Technology, } & \text { Vol. } & 90, & \text { pp }\end{array}$ http://dx.doi.org/10.1016/j.fuproc.2009.06.009

21. Ben, H. and Ragauskas, A. J., One Step Thermal Conversion of Lignin to Gasoline Range Liquid Products by using Zeolites as Additives, RSC Adv., Vol. 2, pp 12892-12898, 2012, http://dx.doi.org/10.1039/c2ra22616b

22. Nilsen, M. H., Antonakou, E., Bouzga, A., Lappas, A., Mathisen, K. and Stöcker, M., Investigation of the Effect of Metal Sites in the Me-Al-MCM-41 ( $\mathrm{Me}=\mathrm{Fe}, \mathrm{Cu}$ or $\mathrm{Zn})$ on the Catalytic Behavior during the Pyrolysis of Wooden Based Biomass, Microporous and Mesoporous Materials, Vol. 105, pp 189-203, 2007, http://dx.doi.org/10.1016/j.micromeso.2007.05.059

23. Oasmaa, A., Leppämäki, E., Koponen, P., Levander, J., and Tapola, E., Physical Characterisation of Biomass-Based Pyrolysis Liquids, Technical Research Centre of Finland, VTT Publication 306, pp 46 plus appendices, 1997.

24. Etzkorn, W. G., Kurland, J. J., and Neilsen, W. D., Acrolein and Derivatives, in Kirk and Othmer's Encyclopedia of Chemical Technology, Vol. 1, 4th ed., John Wiley and Sons, NY, pp 232-251, 1991. 